\title{
PEMODELAN KERANGKA ADAPTIVE THRESHOLD UNTUK MEMONITOR PRODUKSI MINYAK SAWIT NASIONAL BERBASIS STATISTICAL PROCESS CONTROL DAN ARTIFICIAL NEURAL NETWORK-BACKPROPAGATION
}

\author{
modeling adaptive threshold framework for national palm-oil production monitoring \\ based on Statistical Process Control and Artificial Neural Network-Backpropagation
}

\author{
Wahyu Widji Pamungkas ${ }^{1)}$, Syamsul Maarif2), Tun Tedja Irawadi3), Yandra Arkeman ${ }^{4)}$ \\ 1)Program Studi TIP, FATETA IPB, Bogor: wahyuwidji@gmail.com \\ 2) Program Studi TIP an, FATETA IPB, Bogor: wahyuwidji@gmail.com \\ ${ }^{3)}$ Departemen Kimia, FMIPA IPB, Bogor: wahyuwidji@gmail.com \\ 4) Program Studi TIP, Bogor: wahyuwidji@gmail.com \\ (Artikel diterima 8 Juni 2016; direvisi 28 Agustus 2016; disetujui 15 November 2016)
}

\begin{abstract}
Indonesia is the largest exporter of palm oil in the world, as the largest producer Indonesia still have many problems. The problem caused by incomparable between the growth of upstream and downstream palm oil industries. This impact to low added value of palm oil, then Indonesia exports palm oil in crude form. On the other hand, On the other hand, orientation export of this commodity is also prone of barrier, because Indonesia was not the price setter of this commodity in the international market. Therefore it is important to monitor and predict the development of national palm oil production volume in order to take good anticipation. This research develop a framework model adaptive threshold to monitor the growing of national palm oil production volume with techniques of statistical process control (SPC) and back propagation artificial neural network (ANN - BP) methods. Historical data production volume period from 1967 to 2015 was used as a base of the behavior as data to determine the threshold and prediction volume for next periods. The formation of the threshold value was based on the behavior of the historical data, which are oriented by the epicenter of the average value in the last two periods. Through mapping of data historical period values, existing and forecast values with adaptive threshold can show tolerant level for the threshold. Furthermore, based on the analysis, it is known that the prediction of 2016 to 2018 period, there will be happen the dynamics production volume of national palm oil within tolerance threshold. The values of these predictions generated from the simulation model predictions of $A N N-B P$ with the level very good of validation model, demonstrated the level of squared errors is very small' in the MSE $=0.00021136$ with a degree of output correlation and the target is very strong ${ }^{2}$ with $R$ Validation is 99.98 percent.
\end{abstract}

Keywords: adaptive threshold, statistical process control, artificial neural network, national palm oil production.

Ringkasan: Prestasi industri minyak sawit nasional sebagai produsen sekaligus eksportir minyak sawit terbesar di dunia, ternyata faktanya justeru rawan menghadapi perosalan. Pasalnya pertumbuhan industri hulu dan hilir dalam negeri yang jauh dari kata sebanding, mendorong industri minyak sawit nasional berorientasi kepada ekspor dalam bentuk crude yang kurang memberikan nilai tambah di dalam negeri. Di sisi lain, orientasi ekspor komoditi ini juga rawan menghadapi barrier mengingat sejauh ini industri minyak sawit nasional belum mampu menjadi price setter di pasar internasional. Oleh karena itu penting untuk memantau bahkan memprediksi perkembangan volume produksi minyak sawit nasional agar dapat diambil langkah-langkah antisipasinya. Penelitian ini mencoba mengembangkan model kerangka adaptive threshold untuk memantau perkembangan volume produksi minyak sawit nasional berbasis teknik statistical process control (SPC) dan artificial neural network backpropagation (JST-BP). Data historikal volume produksi periode 1967 hingga 2015 digunakan sebagai basis melihat perilaku sekaligus menentukan ambang batas (threshold), serta volume prediksi satu periode kedepan. Pembentukan nilai thresholddidasarkan kepada perilaku data historikal, sehinggaberorientasi berada disekitar episentrum rerata nilai yang ada pada dua periode terakhir. Melalui pemetaan nilai-nilai data periode historikal, eksisting, dan prediksi ke dalam kerangka adaptive threshold, dapat diketahui tingkat toleran terhadap threshold. Selanjutnya berdasarkan analisis, diketahui untuk periode prediksi tahun 2016 hingga 2018, akan terjadi dinamika volume preduksi minyak sawit nasional dalam batas toleransi threshold. Nilainilai prediksi ini dihasilkan dari simulasi model prediksi JST-BP dengan tingkat validasi yang baik yaitu 
MSE $=0.00021136$ untuk menghasilkan prediksi', dengan tingkat korelasi output dan target yang sangat kuat $^{2}$, yakni $R$ Validasi $=99.98$ persen .

Kata kunci: ambang batas adaptif, pengendalian proses secara statistik, jaringan saraf tiruan, produksi minyak sawit nasional.

\section{PENDAHULUAN}

Minyak sawit nasional yang dimaksud dalam tulisan ini adalah keseluruhan volume produk komoditi sawit dalam bentuk CPO (crude palm oil) maupun CPKO (crude palm kernel oil) dan dihitung tahunan secara nasional. Komoditi ini dinilai paling produktif dan paling efisien dalam industri minyak nabati. Tingkat produksinya mencapai 5950 liter/ha/th dan biaya produksi hanya sekitar 30-40 persen dibandingkan dengan minyak nabati lain.

Selama periode 2011-2015, produksi dan konsumsi minyak sawit dunia terus tumbuh, meningkat rata-rata mencapai 4.81 persen dan 5.54 persen pertahun ${ }^{3}$. Peningkatan rata-rata konsumsi lebih tinggi dari produksi ini menggambarkan, di tingkat dunia, industri minyak sawit terus tumbuh dan semakin diperhitungkan. Pertumbuhan industri minyak sawit dunia tidak terlepas dari keberadaan industri minyak sawit nasional dan Malaysia yang memberikan kontribusi tingkat share produksi rata-rata masingmasing sebesar 51.85 persen dan 33.33 persen pertahun. Sementara itu, tingkat share produksi minyak sawit nasional terhadap produksi minyak sawit dunia terus meningkat rata-rata sebesar 1.28 persen pertahun. Akan tetapi sebaliknya terjadi dengan Malaysia, dimana tingkat share produksinya terhadap produksi minyaknabati duniajusteru menurun sebesar 1.45 persen pertahun ${ }^{3}$. Pada sisi lain, data Ditjenbun 2015, menunjukkan bahwa sepanjang tahun 1967 hingga 2015, komoditi minyak sawit nasional selalu terkonsentrasi menjadi komoditi ekspor. Kondisi ini betapa menggambarkan bahwa pertumbuhan industri hilir dan hulu minyak sawit nasional belum sinergis, akibatnya kurang memberikan nilai tambah, bahkan rawan menimbulkan persoalan supply di dalam negeri. Oleh karena itulah penting untuk memodelkan kerangka ambang batas sebagai perangkat pengukuran fluktuasi volume produksi minyak sawit nasional.

Pergerakan volume produksi minyak sawit nasional dapat dipandang sebagai suatu proses kinerja dari industri minyak sawit nasional dan dapat diukur serta dianalisis dengan kerangka pengendalian proses statistik (Statistical Process Controll SPC) melalui pergerakan nilai-nilai historikalnya sebagai basis analisis. Filosofi SPC dikembangkan berdasarkan konsepsi variabilitas proses, yang diterapkan secara luas tidak hanya dalam proses manufaktur tetapi juga dalam operasi proses untuk tujuan kualitas keberlanjutan ${ }^{4}$. SPC merupakan sebuah kerangka pendekatan statistik yang umumnya digunakan dalam memantau dan meningkatkan kinerja proses melalui fungsi salah satunya adalah memantau proses secara terus-menerus sepanjang waktu secara statistikal menggunakan teknik peta Control-Chart. Peta control chart sendiri digunakan untuk: mengetahui apakah telah terjadi perubahan proses produksi, mendeteksi adanya penyebab yang memperngaruhi proses, dan membuat standar proses. Adapun penggunaan control chart meliputi5:

a. Penentuan apakah suatu proses berada dalam pengendalian secara statistikal atau tidak.

b. Pemantauan proses secara terusmenerus sepanjang waktu agar proses tetap stabil secara statistikal dan hanya mengandung variase penyebab umum.

c. Penentuan kemampuan proses (process capability). Setelah proses berada dalam pengendalian statistikal, batas-batas dari variasi proses dapat ditentukan.

Elemen control chart dibagi menjadi 3 bagian utama ${ }^{6,7}$ yaitu : 
a. Garis tengah (Central Line), umumnya dinotasikan dengan $\mathrm{CL}$

b. Batas kontrol (Control Limits), yang terdiri atas:

1) Batas kontrol atas (Upper Control Limits), dinotasikan sebagai UCL yang ditempatkan diatas CL.

2) Batas kontrol bawah (Lower Control Limit), dinotasikan sebagai LCL, dan ditempatkan dibawah CL.

c. Tebaran (Plotting) nilai-nilai dari karakteristik kualitas yang menggambarkan keadan dari proses. Jika tebaran nilai-nilai berada dalam batas-batas kontrol tanpa memperlihatkan kecenderungan tertentu, maka proses yang berlangsung dapat dianggap sebagai kondisi terkontrol dan jika tebaran nilai berada diluar batas-batas kontrol atau cenderung tidak normal, maka proses yang berlangsung diidentifikasi sebagai keadaan di luar kontrol dan berarti memerlukan tindakan korektif.

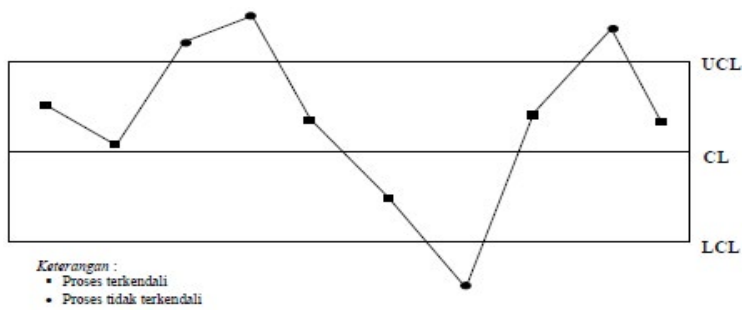

Gambar 1. Kerangka Ambang Batas

Model umum control-chart dari $x$ buah contoh (sample) dapat ditulis sebagai:

$=\mu x-L \alpha x$

$\mathrm{UCL}=\mu \mathrm{x}+\mathrm{L} \alpha \mathrm{x} ; \mathrm{CL}=\mu \mathrm{x} ;$ dan $\mathrm{LCL}$

dan secara umum, rata-rata dari contoh secara statistik dapat dihitung dengan formula:

$$
\mu=\frac{\sum_{i=1}^{N} x_{i}}{N}
$$

Dimana, $\mathrm{N}=$ jumlah contoh.

Sedangkan, standar deviasi dapat dihitung dengan menggunakan formulasi sebagai berikut:

$$
\sigma^{2}=\frac{\sum_{i=1}^{N}\left(x_{i}-\mu\right)^{2}}{N}
$$

atau

$$
\sigma=\sqrt{\sigma^{2}}=\sqrt{\frac{\sum_{i=1}^{N}\left(x_{i}-\mu\right)^{2}}{N}}
$$

Pemodelan kerangka adaptive threshold prediksi volume produksi minyak sawit nasional berbasis teknik statistical process control dan artificial neural networkbackpropagation dikembangkan untuk menghasilkan nilai-nilai kerangka threshold secara adaptif berbasis perilaku historis data dan selanjutnya memetakan dan menilai tingkat kewajaran nilai-nilai prediksi volume minyak sawit nasional yang dipetakan kedalamnya. Nilai-nilai threshold menjadi fungsi pengendali kewajaran nilai-nilai prediksi secara periodik agar terus berada pada jangkauan episentrumnya. Fluktuasi nilai-nilai prediksi yang dipetakan kedalam SPC dan berada diluar thresholdnya dinilai sebagai kejutan yang mengganggu stabilitas kinerja proses. Adapun, nilai-nilai prediksi ini diperoleh dari model prediksi yang dikembangkan berbasis Jaringan Saraf Tiruan propagasi balik (JST-BP) yang dinilai cukup memadai digunakan untuk memprediksi ${ }^{8}$.

\section{Teknik Jaringan Saraf Tiruan (JST)}

JST merupakan salah satu representasi buatan dari otak manusia yang selalu mencoba untuk mensimulasikan proses pembelajaran otak manusia dan dapat digambarkan sebagai model matematis dan komputasi untuk fungsi aproksimasi nonlinear, klasifikasi data kluster dan regresi non-parametrik atau sebuah simulasi dari koleksi model jaringan saraf biologi ${ }^{9,10}$. JST menyerupai otak manusia dalam dua hal, yaitu: pengetahuan diperoleh jaringan melalui proses belajar, dan kekuatan hubungan antar sel syaraf (neuron) ${ }^{8}$ yang dikenal sebagai bobot-bobot sinaptik digunakan untuk menyimpan pengetahuan. JST merupakan sebuah teknik yang dapat diaplikasikan 
dengan baik dibidang peramalan atau prediksi yang ditentukan oleh 3 hal ${ }^{9,11,14:}$

a. Pola hubungan antar neuron (disebut arsitektur jaringan).

b. Metode untuk menentukan bobot penghubung (disebut metode training/ learning).

c. Fungsi aktivasi, yaitu fungsi yang digunakan untuk menentukan keluaran suatu neuron.

Untuk pola hubungan, JST memiliki beberapa arsitektur jaringan dalam aplikasi $^{9,11}$, yakni:

a. Jaringan Layer Tunggal (single layer network).

b. Jaringan layar jamak (multi layer network).

c. Jaringan dengan lapisan kompetitif.

Sementara itu, metode training JST dikelompokkan menjadi 3 kelompok $^{11}$, yaitu:

a. Supervised Learning (pembelajaran terawasi)

b. Unsupervised Learning (pembelajaran tak terawasi)

c. Hybrid Learning (pembelajaran hibrida).

JST menggunakan fungsi aktivasi untuk menentukan keluaran suatu Neuron. Beberapa fungsi aktivasi yang sering digunakan adalah ${ }^{12}$ :

- Fungsi linear atau identitas (purelin), akan menghasilkan nilai-nilai output yang sama dengan nilai-nilai inputnya $y=x$. Secara matematis dinyatakan sebagai:

- Fungsi sigmoid bipolar (tansig), akan menghasilkan nilai output dengan rentang nilai antara -1 hingga 1 melalui fungsi matematik yang dinyatakan sebagai:

$$
y=f(x)=\frac{1-e^{-x}}{1+e^{-x}}
$$

- Fungsi logistik sigmoid (logsig). akan menghasilkan nilai output dengan rentang nilai antara 0 hingga 1 , melalui fungsi matematis yang dinyatakan sebagai:

$$
f^{\prime}(x)=\sigma f(x)[1-f(x)] \quad f(x)=\frac{1}{1+\exp (-\sigma x)}
$$

JST-BP melatih jaringan untuk mendapatkan keseimbangan antara kemampuan jaringan untuk mengenali pola yang digunakan selama pelatihan serta kemampuan untuk memberikan respon yang benar terhadap pola masukkan yang serupa dengan pola yang dipakai selama pelatihan ${ }^{12}$. Algoritma pelatihan jaringan syaraf perambatan galat (error) mundur terdiri atas dua langkah, yaitu perambatan maju dan perambatan mundur. Langkah perambatan maju dan peramabatan mundur ini dilakukan pada jaringan untuk setiap pola yang diberikan selama jaringan mengalami pelatihan ${ }^{13}$. Siklus perubahan bobot (epoch) dilakukan pada setiap set pelatihan sehingga kondisi berhenti dicapai, yaitu bila mencapai jumlah epoch yang diinginkan atau hingga sebuah nilai ambang yang ditetapkan terlampaui. Algoritma pelatihan JST-BP melalui 3 tahap ${ }^{14}$, yakni: tahap umpan maju (feedforward), tahap umpan mundur (backpropagation), dan tahap perbaikan bobot dan bias.

\section{BAHAN DAN METODE}

Metode yang digunakan dalam penelitian ini adalah sebagai berikut:

Pertama, mengumpulkan dan mengolah Data. Data yang dikumpulkan dan diolah merupakan data tahunan volume produksi minyak sawit nasional secara historikal dari tahun 1967 hingga 2015, berasal dari sumber utama, Ditjenbun tahun 2014 dan USDA 2016 serta dari sumber pendukung lainnya.

Kedua $_{1}$ menghitung nilai-nilai parameter statistik. Berdasarkan data historikal, selanjutnya dihitung nilai-nilai maksimum, minimum, rata-rata, dan median. Nilai data tahun 2015 dianggap sebagai nilai akhir yang menjadi pembatas periode eksisting dengan tahun awal periode prediksi. Satu periode ditentukan sebagai kurun waktu 3 tahunan yang dinilai representatif terhadap deret waktu tahunan yang digunakan untuk mengamati pola sekaligus memperhatikan kecepatan perubahan dalam industri minyak sawit. 
Ketiga $_{2}$ melakukan ploting data historikal ke dalam chart control. Berdasarkan data historikal yang telah dilengkapi dengan nilainilai parameter statistik standar, selanjutnya dilakukan ploting ke dalam control chart. Ploting ini bertujuan untuk memetakan nilainilai dalam kerangka ambang batas yang nilai-nilai ditentukan kemudian berdasarkan perilaku data dua periode terakhir, yaitu periode eksisting, dan satu periode historikal terakhir.

Keempat $_{2}$ memodelkan kerangka adaptivethreshold dalam control chart. Selanjutnya berbasis pada perilaku dua periode terakhir sebagai basis prediksi, dengan memperhatikan nilai akhir dari data tahun terakhir periode eksisting dihitung dan digambarkan ambang batas (threshold) maksimum dan minimumnya untuk selama periode prediksi.

Kelima $_{2}$ merancang model prediksi JST-BP. Pada sisi yang lain, berbasis pada data runtun waktu tersebut, dilakukan perancangan model prediksi JST-BP terbaik yang dapat diketahui melalui parameter- parameter kinerja (performance) model JST. $K_{\text {Keenam }}$ Simulasi model prediski JSTBP terbaik. Simulasi model prediksi JST-BP yang terbaik digunakan untuk menghasilkan atau membangun nilai-nilai prediksi volume minyak sawit nasional selama kurun waktu tiga tahun prediksi.

$K_{\text {Ketujuh }}{ }_{2}$ Ploting nilai-nilai hasil prediksi ke dalam control chart adaptive threshold. Selanjutnya, terhadap nilai-nilai prediksi hasl simulasi model JST-BP, ditambahkan dalam ploting control chart adaptive threshold, untuk mengetahui keberadaan prediksi terhadap threshold maksimum dan minimumnya.

\section{HASIL DAN PEMBAHASAN}

Pengumpulan dan pengolahan terhadap data volume minyak sawit nasional tahunan kurun waktu tahun 1967 hingga 2015, mengacu pada periodesasi, dimana digunakan tiga jenis periode yakni: periode eksisting, periode historikal, dan periode prediksi. Setiap periode merupakan kurun waktu 3 tahunan, seperti disajikan dalam gambar periode analisis berikut ini:

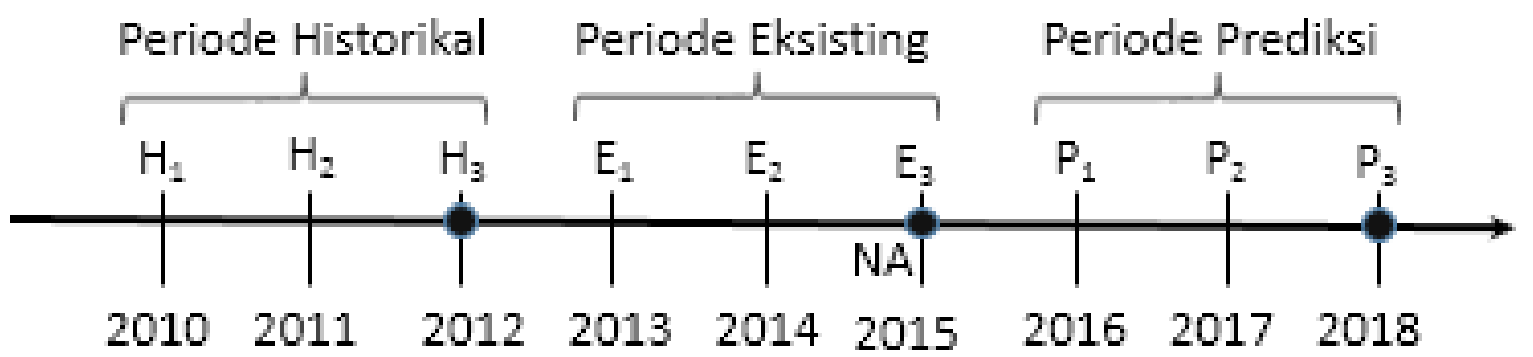

Gambar 2. Periodesasi Analisis

Selanjutnya berdasarkan data periodesasi tersebut dihitung nilai-nilai parameter statistik standar,dimana untuk periode enam tahun terakhir (satu periode eksisting dan satu periode historikal terakhir) diperoleh ploting data dan nilai-nilai parameter statistik standar sebagai berikut: 


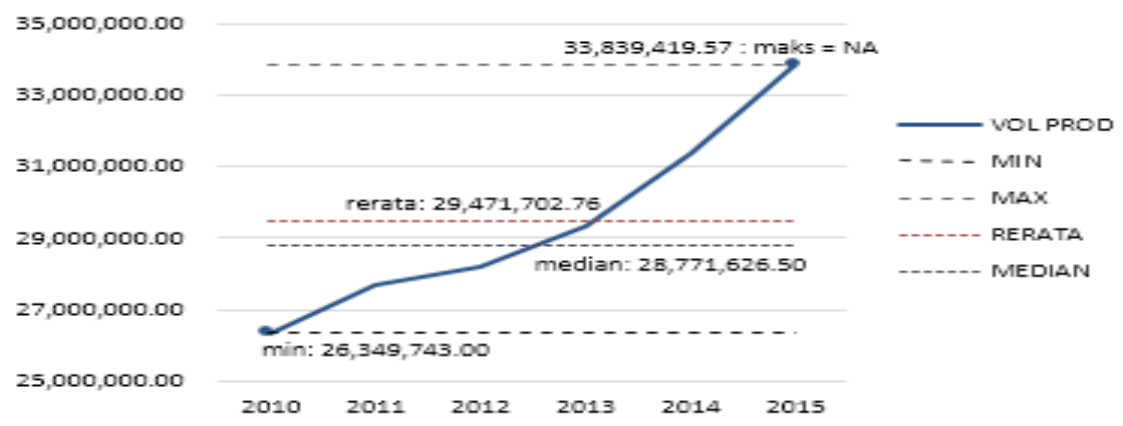

Gambar 3. Ploting Data Periode Eksisting dan Historikal

- Minimum (maks)

$: 26,349,743$

- Maksimum (min)

: $33,839,420$

- Rerata (R)

: 29,471,703

- Median (M)

: $28,771,627$

- Nilai Akhir $\Rightarrow \mathrm{NA}=$ maks.

\section{Pemodelan Kerangka Adaptive Threshold}

Proses prediksi dan deteksi merupakan prosesmenilaipolaperubahan nilai-nilai variabel pada rentang waktu historis tertentu menuju waktu yang akan datang terhadap kerangka ambangbatas (threshold) yang digunakan. Nilai-nilai threshold ditentukan berdasarkan distribusi nilai-nilai periode eksisting dan satu periode historis sebelumnya. Pergerakan nilainilai prediksi yang melampaui nilai thresholdnya, merupakan suatu kejutan atau anomali yang mengindikasikan sesuatu terjadi diluar kebiasaan dan dinilai akan merugikan. Rentang nilai-nilai threshold ditentukan sedemikian rupa sehingga batas kewajaran ditarik mendekat ke pusat distribusinya (rerata). Kenaikan maupun penurunan volume produksi minyak sawit nasional secara drastis atau ekstrim adalah kejutan yang akan menciptakan sentimen negatif, oleh karena harus dihindari. Secara matematis nilai-nilai threshold ditentukan dengan formulasi:

(i) untuk $N A=$ Maks atau $N A=$ Min

digunakan formulasi sebagai berikut: $n$-thres $=N A-((N A-M) / 2)-\{(($ Maks Min) / Maks $) *($ Maks $-R)\}$ $m$-thres $=N A+((N A-M) / 2)-\{(($ Maks Min) / Maks $){ }^{*}($ Maks $\left.-R)\right\}$

(ii) sedangkan untuk NA \# Maks dan NA \# Min digunakan formulasi sebagai berikut: $n$-thres $=N A+\{($ Max $-M) / 2\}$

\author{
$m$-thres $=N A-\{(M-M i n) / 2\}$ \\ dimana $N A=$ nilai akhir periode \\ berjalan \\ Maks = nilai maksimum periode \\ historis dan berjalan \\ Min = nilai minimum periode \\ historis dan berjalan \\ Rerata = nilai rata periode historis \\ dan berjalan \\ m-thres $=$ nilai threshold maksimal \\ periode prediksi \\ n-thres= nilai threshold minimal periode \\ prediksi
}

Mengacu pada ploting data diatas, diketahui bahwa nilai akhir (NA) sama dengan maksimum (maks), dengan demikian penentuan nilai ambang batas (threshold) maksimum dan minimumnya adalah menggunakan formulasi (i), yaitu:

n-thres $=N A-((N A-M) / 2)-\{(($ Maks -

Min) / Maks) * (Maks $-R)\}$

$=33,839,420-((33,839,420-$

$28,771,627) / 2)$

$\{((33,839,420-26,349,743) /$

$33,839,420) *(33,839,420-$

$29,471,703)\}$

$=30,338,816.55$

m-thres $=N A+((N A-M) / 2)-\{(($ Maks -

Min) / Maks) * (Maks $-R)\}$

$=33,839,420+((33,839,420-$

$28,771,627) / 2)$

$\{((33,839,420-26,349,743)$

$/ 33,839,420) *(33,839,420$ -

$29,471,703)\}$

$=35,406,609.62$ 
selanjutnya dilakukan ploting adaptivethreshold sebagai berikut: kembali, maka menghasilkan kerangka

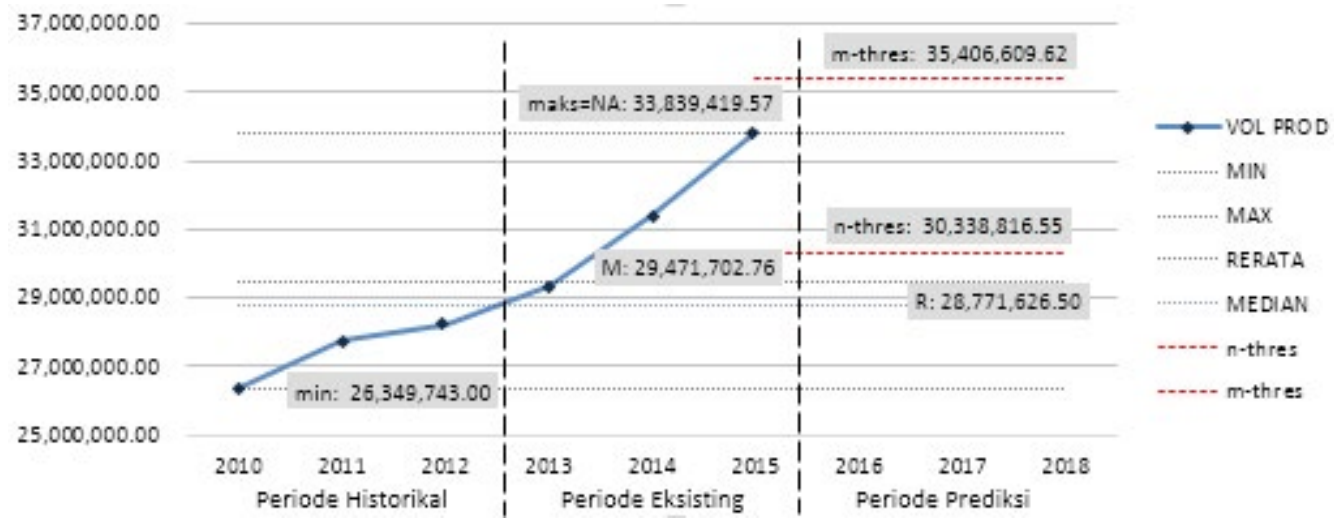

Gambar 4. Kerangka Threshold Adaptif Prediksi Volume Produksi Minyak Sawit Nasional.

\section{Perancangan Model Prediksi JST-BP}

Rancangan arsitektur menentukan baik-buruknya suatu model JST yang dihasilkan. Namun demikian jumlah dan susunan neuron-neuron dalam lapisan tidak dapat ditentukan secara pasti melainkan melalui cara coba-coba (trial and error) dan bergantung pada pengalaman perancang dalam mengaplikasikan $\mathrm{JST}^{15}$. Berdasarkan beberapa percobaan yang dilakukan melalui paramater-parameter rancangan model JSTBP:

- goal $: 1 \mathrm{e}-10$

- learning rate :0.01

- maxepoch :1000

- fungsi transfer : purelin untuk semua lapisan

- algoritma :training LevenbergMarqurdt, performance MSE, data division Random

- data input :matrik 3x46

- data output :matrik 1x46

- data normalized : zScore

- validation metode: K-Fold Cross Validation $60 \%$ training, $20 \%$ validasi dan $20 \%$ testing:

Diperoleh hasil struktur model prediksi JST-BP terbaik sebagai berikut:

- jumlah layer: 3 (terdiri dari 1 layer input, 1 layer tersembunyi, dan 1 layer output)
- total neuron: 7 (terdiri dari 3 neuron di layer input, 3 neuron di layer tersembunyi, dan 1 neuron di layer output).Septiani

- fungsi aktivasi: seluruhnya purelin

Adapun nilai-nilai parameter validasi model prediksi JST-BP yang dihasilkan, adalah sebagai berikut:Performance training, testing, dan validasi ditunjukkan dalam gambar 14., dimana tingkat performance validasi terkecil dicapai pada epoch ke-4 dengan nilai MSE (kuadrat error) sebesar 0.00021136

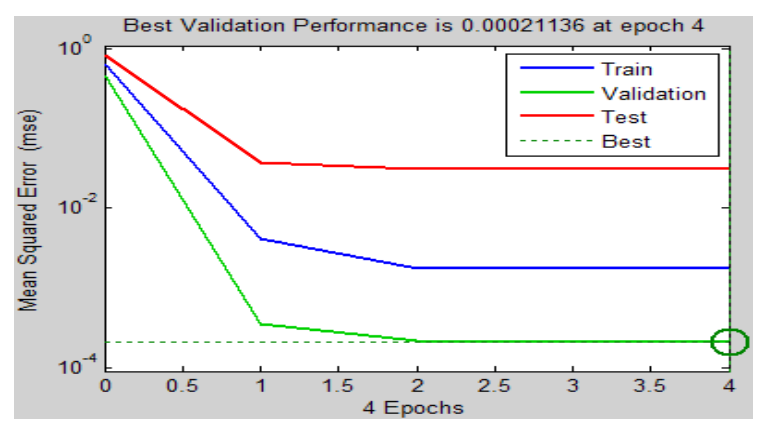

Gambar 5. Grafik Kinerja Pelatihan Jaringan

Sedangkan koefisien korelasi $r$ yang menunjukkan makna kekuatan, signifikansi, dan arah hubungan antara output dengan target $^{2}$ yang dihasilkan adalah sebagai berikut:

- R Training : 0.99908 atau $99.91 \%$

- R Validasi : 0.99984 atau $99.84 \%$ 
- R Test : 0.98880 atau $98.88 \%$

- R All : 0.99635 atau $99.64 \%$

Dengan demikian seluruhnya menunjukkan angka korelasi $r$ mendekati 1 , yang berarti korelasi antara output dengan targetnya selama proses training, validasi, test, dan secara keseluruhan adalah sangat kuat ${ }^{2}$.

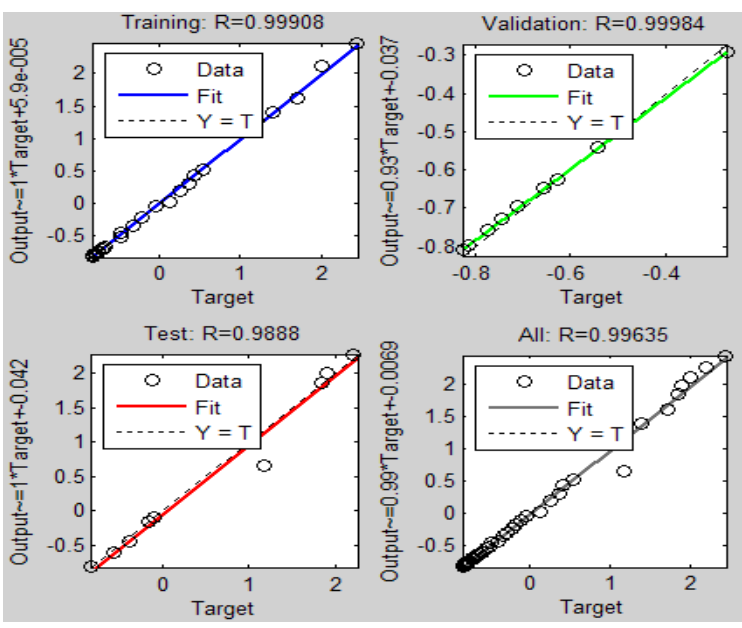

Gambar 6. Grafik Korelasi Output dengan Target

\section{Simulasi Model Prediksi JST-BP}

Simulasi terhadap hasil model prediksi JST-BP, menunjukkan bahwa Prediksi ${ }_{(n)}=$ sim (net, data ${ }_{(\mathrm{n})}$ ) berturut-turut menghasilkan nilai prediksi volume minyak sawit nasional P1, P2, dan P3 seperti ditunjukkan pada tabel berikut ini.

Tabel 1. Hasil Simulasi Model Prediksi JSTBP Periode Prediksi 2016-2018.

\begin{tabular}{|c|c|c|c|c|c|}
\hline \multicolumn{6}{|c|}{ Tahun } \\
\hline 2013 & 2014 & 2015 & $\begin{array}{l}2016 \\
\text { (P1) }\end{array}$ & $\begin{array}{r}2017 \\
\text { (P2) }\end{array}$ & $\begin{array}{c}2018 \\
\text { (P3) }\end{array}$ \\
\hline \multirow[t]{3}{*}{$\begin{array}{c}29,317 \\
968\end{array}$} & $\begin{array}{c}31,381 \\
952\end{array}$ & $\begin{array}{c}33,839, \\
420\end{array}$ & $\begin{array}{c}32,913 \\
000\end{array}$ & & \\
\hline & $\begin{array}{c}31,381 \\
952\end{array}$ & $\begin{array}{c}33,839 \\
420\end{array}$ & $\begin{array}{c}32,913 \\
000\end{array}$ & $\begin{array}{c}32,143 \\
000\end{array}$ & \\
\hline & & $\begin{array}{c}33,839, \\
420\end{array}$ & $\begin{array}{c}32,913 \\
000\end{array}$ & $\begin{array}{c}32,143 \\
000\end{array}$ & $\begin{array}{c}32,383, \\
000\end{array}$ \\
\hline
\end{tabular}

Selanjutnya nilai-nilai hasil prediksi volume produksi minyak sawit nasional untuk tahun 2016 hingga 2018 (P1, P2, dan P3) di ploting ke dalam kerangka adaptivethreshold (threshold) adalah seperti pada gambar grafik di bawah ini.

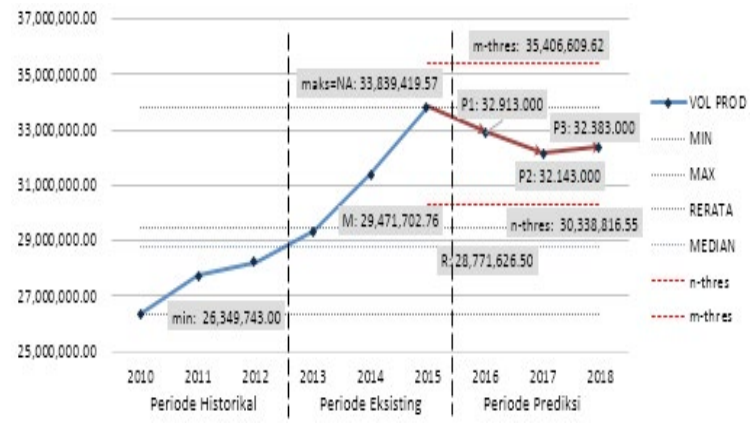

Gambar 7. Ploting Hasil Prediksi dalam Kerangka Threshold Adaptif

Dengan demikian dapat diketahui bahwa volume produksi minyak sawit nasional diprediksi pada periode tahun 20162018 akan mengalami penurunan kecil pada tahun pertama dan kedua, serta selanjutnya meningkat kembali kecil pada tahun ketiga periode prediksi. Pergerakan kecil volume produksi ini jika dilihat dari kerangka adaptive threshold di atas masih berada dalam ambang batas kewajaran karena berada di atas nilai minimum threshold dan di bawah nilai maksimum threshold.

\section{SIMPULAN}

Tren peningkatan volume produksi minyak sawit nasional selama dua periode terakhir yaitu periode historis (2010-2012) dan periode eksisting (2013-2015) menunjukkan terjadi kecenderungan peningkatan ekstrim. Perilaku kecenderungan ini membentuk model kerangka threshold yang dihasilkan untuk menarik batas maksimum dan minimum threshold volume produksi minyak sawit nasional pada periode prediksi (20162018) agar mendekat terkonsentrasi disekitar nilai rata-ratanya (dua periode terakhir tersebut). Dengan demikian model kerangka threshold tersebut bersifat adaptif dan objektif bergantung dari perilaku pola data pada dua periode terakhir yang membentuknya.

Adapun Besaran jangkauan penarikan ini, ditentukan oleh nilai akhir (NA) dari data analisis yang kemudian menentukan 
formulasi yang digunakan, yaitu berlaku: formulasi (i), dimana threshold ditarik ke arah episentrum nilai-nilai yang menjadi perilaku dua periode tarakhir. Sementara itu, hasil simulasi terhadap model prediksi JST-BP, menunjukkan bahwa sepanjang periode prediksi (2016-2018), nilai-nilai prediksi volume produksi minyak sawit nasional yang dihasilkan akan berada pada rentang toleransi threshold-nya, sehingga diprediksi tidak akan menimbulkan persoalan supplay minyak sawit di dalam negeri.

\section{DAFTAR PUSTAKA}

1. Ch. Jyosthna Devi et al. ANN Approach for Weather Prediction using Back Propagation. International Journal of Engineering Trends and Technology. 2012; 3(1): 19-23; ISSN: 2231-5381.

2. Tuti Budiwati, Afif Budiyono, Wiwiek Setyawati, Asri Indrawati. Analisis Korelasi Pearson untuk Unsur-Unsur Kimia Air Hujan di Bandung. Jurnal Sains Dirgantara. Bandung. 2010; 7(2): 101-112.

3. United States Department of Agriculture: Foreign Agricultural Service, Approved by the World Agricultural Outlook Board. Oilseeds: World Markets and Trade. [internet]. 2016 [Data Created 9 Feb 2016]. Tersedia di: http://apps.fas.usda. gov/psdonline/

4. Ali Mostafaeipour, Ahmad Sedaghat, Ali Hazrati and Mohammadali Vahdatzad. Article: The use of Statistical Process Control Technique in the Ceramic Tile Manufacturing: a Case Study. International Journal of Applied Information Systems. New York. 2012; 2(5):14-19.

5. Hayu Kartika. Analisis Pengendalian Kualitas Produk CPE Film Dengan Metode Statistical Process Control Pada PT MSI. Jurnal IImiah Teknik Industri, Universitas Mercu Buana. Jakarta. 2013; 1(1): 50-58.

6. Nurul M.S., Panji W.W., dan Satriya A. Perancangan dan Implementasi Jaringan Saraf Tiruan Backpropagation untuk Mendiagnosa Penyakit Kulit. Jurnal
Masyarakat Informatika, Universitas Diponegoro. Semarang. 2014; 5(10): 9-18; ISSN 2086-4930

7. Jayalakshmi T., and Santhakumaran. Statistical Normalization and Back Propagation for Classification. Internasional Journal of Computer Theory and Engineering. 2011; 3(1): 8993.

8. Muhamad Irvan M., Much Aziz M. Sistem Prediksi Tagihan Listrik Usaha Jasa Laundry Menggunakan Jaringan Saraf Tiruan Backpropagation. Jurnal Matematika, Universitas Negeri Semarang. Semarang. 2015; 4(1); 5866.

9. Febrianto, Dany Candra dan Mustafidah, Hindayati. Penerapan Jaringan Saraf Tiruan untuk Mengetahui Tingkat Kualifikasi Calon Siswa pada Sistem Informasi Penerimaan Siswa Baru di MAN 2 Banjarnegara. Jurnal Informatika, Universitas Muhammadiyah Purwokerto. 2013; 2(3): 189-197; ISSN 2086-9398.

10. Maria A., Toni P. Penggunaan Jaringan Syaraf Tiruan Backpropagation Untuk Seleksi Penerimaan Mahasiswa Baru Pada Jurusan Teknik Komputer Di Politeknik Negeri Sriwijaya. Jurnal Sistem Informasi Bisnis, Universitas Diponegoro. Semarang. 2012; 2(1):89-97.

11. Arif Jumarwanto. Aplikasi Jaringan Saraf Tiruan Backpropagation untuk Memprediksi Penyakit THT di Rumah Sakit Mardi Rahayu Kudus. Jurnal Teknik Elektro, Uiversitas Negeri Semarang. Semarang. 20010; 1(1): 11-21.

12. Zekson Arizona Matondang. Jaringan Saraf Tiruan dengan Algoritma Backpropagation untuk Penentuan Kelulusan Sidang Skripsi. Jurnal Pelita Informatika Budi Darma, STIMIK Budi Darma. Medan. 2013; 4(1): 84-93; ISSN: 23019425.

13. Jonas E. G., Rintis H., dan Setiono. Prediksi Potensi Debit Berdasarkan Data Hujan Maksimum Bulanan Dengan Metode Jaringan Syaraf Tiruan Backpropagation Di Das Alang. e-Jurnal Matriks Teknik Sipil, Universitas Sebelas 
Maret. Surakarta. 2014; 2(1); 55-62; ISBN: 2354-8630.

14. Amit G., Y.P. Kosta, Gaurang P., Chintan G. Initial Clasification Through Back Propagation In a Neural Network Following Optimization Through GA to Evaluate the Fitness of an Algorithm. International Journal of Computer Science \& Information Technology (IJCSIT). 2011; 3(1): 98-116; DOI : 10.5121/ijcsit.2011.3108.
15. Heri Eko P., Rintis H., Setiono. Analisis Data Runtun Waktu Debit Menggunakan Jaringan Saraf Tiruan di DAS Wuryantoro Pada AWLR Kecamatan Wuryantoro. e-Jurnal Matriks Teknik Sipil, Universitas Sebelas Maret. Surakarta. 2014; 2(2): 64-71; ISSN: 2354-8630. 